\title{
BK-virus (BKV) - structure, epidemiology and pathogenesis
}

\author{
Dorota Polz' ${ }^{1}$, Agnieszka Stec ${ }^{1}$, Małgorzata Polz-Dacewicz ${ }^{1}$ \\ ${ }^{1}$ Department of Virology, Medical University, Lublin, Poland \\ Polz D, Stec A, Polz-Dacewicz M. BK-virus (BKV) - structure, epidemiology and pathogenesis. J Pre-Clin Clin Res. 2013; 7(2): 90-92.
}

\section{Abstract}

The number of cancers is constantly growing. An important role in the etiology of many of them is played by aviral factor - by oncogenic viruses. This group of viruses, according to many researchers, also includes the BK virus (BKV). The article describes the structure of the virus, current epidemiological situation, and modes of transmission. It also explains the BKV induced oncogenesis and the role of the virus in the development of cancer.

\section{Key words}

BK virus, pathogenicity, cancers, tumours

\section{INTRODUCTION}

Oncogenic viruses play an important role in the development of various types of cancer. One of those viruses is probably the BKV. The virus was first isolated by Gardner at al. in 1971 from the urine of a renal transplant recipient and named from the initials of the patient [1]. This virus belongs to the Polyomaviridae family, with other known human polyomavirus members such as JCV and recently discovered KIV, WUV, polomaviruse-6, -7, -9 and MCV (Merkel cell polyomavirus). BKV is closely related to JCV, with the sequence homologies of approximately 75\% [2], and BKV has less homology with novel polyomaviruses. According to recent recommendations of the Polyomaviridae Study Group of International Committee on Taxonomy of Viruses (ICTV), $\mathrm{BKV}$ belongs to the Orthopolyomavirus genus, together with JCV and MCV [3].

Virus structure and genome organization. BKV is non-enveloped, small-sized virus, approximately $40 \mathrm{~nm}$ in diameter. The icosahedral capsid is composed of 72 capsomers enclosed in a single molecule of covalently closed circular double-stranded DNA. The genome averages approximately 5 kilobasepairs in length. The genome sequence can be divided into three functional regions: the early, late and non-coding control region (NCCR). The early encodes small and large T-antigens (t-Ag and T-Ag) which are essential for viral DNA replication regulation and viral expression. T-antigen has an oncogenic potential. It leads to immortalization and transformations of cultured (animal, rodent) cells as it interacts with tumour suppressor p53 and $\mathrm{pRb}$ family proteins. The products of the late region are the structural proteins VP1, VP2 and VP3. The last region (NCCR) contains elements for expression control of early and late genes [4]. Different forms of BKV are distinguished including the named archetype (wild, WW) virus and rearranged variants with different mutations in the noncoding control region (NCCR). Some researchers propose an archetype hypothesis that archetypal BKV strains are a wild type of virus, which circulates in the human population, others suggest that rearranged variants are generated from

Address for correspondence: Dorota Polz, Department of Virology, Medical University, 20-093 Lublin, Poland

e-mail: dorota.polz@umlub.pl

Received: 01 August 2013; accepted: 04 February 2014 archetypal variants of BKV during persistence in the host. So far, it is not known whether genetic alterations are essential for the pathogenesis of BKV [5]. BKV isolates have been classified into four genotypes (I-IV) based on the sequence of VP1 variable region (TR typing region). The analyses of BKV world distribution have shown that virus subtypes are geographically distributed, and some investigators suggest they reflect human population migration patterns (comigration hypothesis) [6].

The most prevalent in all examined populations is type $\mathrm{I}$, which is further subdivided into Ia, Ib-1, I-b-2 and Ic subgroups. In the European populations, Ib-2 is predominant [7].

Subtype IV (divided into six subgroups) is less common and subtype II and III are rare, although in some reports subtype III has been detected more frequently in HIV-infected patients [8]. Several data have suggested that the presence of immunossupression does not influence the distribution of BKV subtypes. A number of studies has been conducted to determine the clinical significance of different BKV subtypes (genetic diversity); however, its significance remains unclear. No correlation between subtypes and clinical characteristics has been demonstrated to-date [7].

Epidemiology and transmission. The transmission of BKV is unclear, debated and investigated. There are several possible modes of transmission: via the respiratory tract (in tonsils of children), through saliva, uro-oral, faecal-oral route, bloodborne (carriage in leucocytes), and via the sexual route (BKV DNA has been detected in prostate tissues and seminal fluids). There is also the possibility of a transplacental transmission. An important reservoir of BKV is soiled water $[9,10,11]$.

Some authors provide other ways of transmission: blood transfusion, organ transplantation, and through close contact [12]. According to current data, $75 \%-90 \%$ of the general population may be seropositive $[10,13,14,15]$, and the change of status to seropositive appears in childhood, between the ages 5 - 10 [16]. After initial infection, BKV is not eliminated from the host, it establishes a latent state and persists mainly in kidney epithelial cells. Other locations of the virus may also include the lymphocytes (BKV DNA was detected in liver, lungs and lymph nodes) $[17,18]$. Sometimes, the virus reactivates and is asymptomatically shed into the urine and viruria can be detected. This virus is detected in the urine of $5-10 \%$ immunocompetent adults, and additionally, viruria 
is observed in approximately $25-50 \%$ of pregnant women $[14,19,20,21]$. BKV infection is generally asymptomatic or has flu-like symptoms, the urogenital tract is the main site for non-replicative infection $[13,22,23]$. Symptomatic BKV infections occur in immunocompromised patients, and among organ transplant recipients $[13,24]$.

BKV diagnostics and treatment. The gold standard for the diagnosis of BKVAN is an immunohistological examination of renal biopsy [25]. The most common, however, are noninvasive methods, such as urine cythology, microscopy detection of epithelial cells termed decoy cells with typical inclusions in the nucleus, and peripheral rim of chromatin. The best marker in the follow-up of patients is viral load in plasma and urine samples with quantitative assays (i.e. realtime $\mathrm{qPCR}$ ). It is a useful tool in the prospective monitoring of BKV reactivation, and prevention of its clinical outcomes. Patients with active infection generally have detectable BKV DNA in plasma (viraemia) and higher levels of viruria [26, 27]. According to some researchers, a considerable viruria (cut-off value of $\geq 107 / \mathrm{ml}$ ) is a risk factor for the development of nephropathy, and as a result may lead to viraemia and the progression of BKVAN $[28,29]$. qPCR is very sensitive and has a wide dynamic range, thus it could be used in the monitoring of therapy effects. Experts on transplantation programmes have recommend BKV screening.

The therapy of BKV reactivation is mainly based on the reduction of immunosupression dosage to improve the host antiviral immunoresponse. A key role is played by rapid detection of the virus and restoring immunity in order to reduce viral replication [9]. There is no effective BKV-specific treatment; however, some researchers have reported cidofovir (nucleotide analogue of cytosine) therapy to be successful [9, 30]. This analogue to cytosine should be used with caution because it is highly nephrotoxic for tubular cells $[9,32]$. Another drug used is leflunomide, which blocks dihydroorotate dehydrogenase, tyrosine kinase and pyrimidine synthesis. It is a drug used in the treatment of rheumatoid arthritis, and combined with the reduction of imminosupression it is used in treating BKV-associated diseases.

Fluoroquinolones (e.g. ciprofloxacin) inhibit the synthesis of bacterial DNA, but also have activity against viral helicase, TAg. They are used in combination with immunosuppression reduction in the anti-viral therapy $[9,12,14,31]$. Efforts are being made for using intravenous application of immunoglobulins containing antibodies neutralizing $\mathrm{BKPyV}[9,14]$.

There are many studies reporting clinical implications of $\mathrm{BKV}$ infection in transplant recipients, and because this is an increasingly recognized complication, the BKV may be designated as an emerging pathogen $[14,33]$.

$\mathrm{BKV}$-associated diseases. $\mathrm{BKV}$ reactivation is a serious problem among immunocompromised individuals, especially among patients with immunosupresive therapy following transplantation. Approximately $10-60 \%$ of renal transplant recipients and almost $50 \%$ of bone marrow recipients develop $\mathrm{BKV}$ reactivation, which results in nephropathy (BKVAN$\mathrm{BK}$ virus associated nephropathy) or haemorrhagic cystitis (HC, a disease of the bladder) in about $8 \%$ of cases [28, 29].

The progression of these syndromes strongly depends on immunosupression specific agents. BKVAN clinically resembles graft rejection and is characterized by graft dysfunction and even graft loss. Signs of renal dysfunction that suggest BKV reactivation include the presence of haematuria and increase in serum creatinine [34].

According to van Aalderen [10], BKV may be found in urothelial cells, cervical squamous epithelial cells, peripherial blood leucocytes, salivary gland cells, and prostate glandular epithelial cells. BKV has been detected in urine and seminal fluid, but never in plasma. BKV is correlated with many clinical manifestations: BKV nephropathy, ureteral stenosis, and haemorrhagic cystis. Discussions are currently being held on the correlations between BKV and encephalitis, retinitis, infections of the respiratory tract and vasculopathy [10].

The role of BKV in neoplasia is still being investigated, and due to conflicting reports, is controversial. Some authors have shown a high prevalence of BKV in precancerous cervical lesions, and confirm that $\mathrm{BKV}$ is associated with this type of lesion. It is also possible that BKV is a co-factor for HPV in cervical cancer $[35,36]$.

BKV DNA has been detected in many tumours located in various places, including rhabdomyosarcoma, lungs, Kaposi's sarcoma, pancreas, liver, brain, and the urinary tract. Some researchers negate the evidence of BK virus as the factor causing brain tumours, urothelial carcinoma of the bladder, renal pelvis, meningiomas, and medulloblastomas $[36,37]$. BKV-IR (BKV variant DNA) was detected in human insulinoma. In a different study, BKV DNA was detected in $46 \%$ of brain tumours and neuroblastomas, in $20 \%$ of cases of Kaposi's sarcoma, and in $60 \%$ of urinary tract tumours. Additionally, BKV DNA has been detected (using PCR) in the uterine cervix, vulva, lips and tongue carcinomas [11].

The main location of BKV latency - the urinary tract suggests that $\mathrm{BKV}$ is associated with urinary tract carcinomas (e.g. bladder, kidney, prostate cancer). On the other hand, despite BKV DNA detection, its role is not confirmed in malignant glioma, medulloblastoma, bladder carcinoma, Kaposi's sarcoma, lymphoma, and acute lymphoblastic leukemia. Scientists excluded the role of BKV in breast carcinoma [38] and in bladder cancer $[39,40]$.

BKV-dependent oncogenesis. T antigen (Tag, large T antigen) is responsible for changes in the cells' physiology, which in extreme cases may lead to neoplastic transformation. T antigen plays two major roles: it regulates viral origins of DNA replication and interacts with proteins involved in cell cycle development [41]. T antigen is responsible for leading to immortalization and neoplastic transformation of infected cells. Tag has the ability to bind and block the functions of p53 and pRB family (p105, RB1, p107, p130) which are tumour suppressor proteins; thus, Tag disorganizes normal cell growth. In effect, blocking of apoptosis and alleviating the cell cycle block occurs. The consequence of still expression of Tag was observed during BKV transformation in mouse and hamster cells [42]. Tag's activity can be divided into several steps: first, 'persuading' the cell to enter the S phase of the cell cycle (cells that are attacked are those which do not divide actively, e.g. urinary epithelial cells or respiratory epithelial cells). Because during the replication of viral DNA, polyomaviruses need the host machinery, the virus then 'cheats' the cells so that they begin to divide (duplication of the viral DNA). Tag makes this possible through blocking the family of tumour suppressor proteins ( $\mathrm{pRb}, \mathrm{p} 107, \mathrm{p} 130)$. After the cells enter the $S$ phase, Tag blocks and inactivates the $\mathrm{p} 53$ protein, preventing apoptosis and, in effect, causing uncontrollable cell division. In addition, Tag has the ability to induce chromosomal damage, 
although the mechanism of this process is unclear [43]. Tag influences cellular growth mechanisms; however, additional factors are required for the transformation of infected cells by the BKV [42]. BKV DNA has the ability to transform embryonic fibroblasts and cells cultured from the brains and kidneys of mice, rats, rabbits, hamsters and monkeys. In the mentioned studies, the expression of $\mathrm{T}$ antigen of the $\mathrm{BKV}$ occurring in the nucleus of all cells in the culture was observed. DNA recombination containing BKV Tag gene and activated through c-Ha-ras oncogene (pBK/c-rasA) induces the neoplastic transformation of early-passage hamster embryo cells with a greater effectiveness than when each gene is transfected independent of one another. Thus, a synergetic effect between BKV Tag and c-Ha-ras is possible. Apart from that, BKV induces the development of tumours in the experimental mode on laboratory animals; in transgenic mice it can lead to the development of hepatocellular carcinoma and renal tumours [37, 42, 44, 45].

To summarise: the following facts may be evidence of the possible oncogenic potential of the BK virus: it has the ability to transform cells in a culture, has the ability to induce tumours in laboratory animals, and the presence of BKV DNA and viral oncoprotein expression has been found to be associated with some cancers [41].

\section{REFERENCES}

1. Gardner SD, Field AM, Coleman DV, Hulme B. New human papovavirus (B.K.) isolated from urine after renal transplantation. Lancet. 1971; 1:1253-1257.

2. Frisque RJ, Bream GL, Cannella MT. Human polyomavirus JC genome. J Virol. 1984; 51: 458-469.

3. Johne R, Buck CB, Allander T, Atwood WJ, Garcea RL, Imperiale MJ. et al. Taxonomical developments in the family Polyomaviridae. Arch Virol 2011; 156: 1627-1634.

4. Imperiale MJ, Major EO. Polyomaviruses. In: Knipe DM, Howeley PM, eds. Fields Virology. $5^{\text {th }}$ ed. Philadelphia, Lippincott Williams\&Wilkins, 2007.p. 2263-2298

5. Yogo Y, Sugimoto Ch, Zhong S, Homma Y. Evolution of the polyomavirus: epidemiological, anthropological and clinical implications. Rev Med Virol. 2009; 19: 185-199.

6.Zhong S, Randawa PS, Ikegaya H, Chen Q, Zheng HY, Suzuki M. et al. Distribution patterns of BK polyomavirus (BKV) subtypes and subgroups in American, European and Asian populations suggest comigration of BKV and the human race. J Gan Virol. 2009; 90: 144-152.

7.Ikegaya H, Saukko PJ, Tertti R, Metsärinne KP, Carr MJ, Crowley B. et al. Identification of genomic subgroup of BK polyomavirus spread in European populations. J Gen Virol. 2006; 87: 3201-3208.

8. Walker DL, Padgett BL. The epidemiology of human polyomaviruses. Prog Clin Biol Res. 1983; 105: 99-106.

9. Siguier M, Sellier P, Bergmann J-F. BK-virus infections: A literature review. Medècine et maladies infectieuses. 2012; 41: 181-187.

10. Van Aalderen MC, Heutinck KM, Huisman C, ten Berge IJM. BK virus infection in transplant recipients: Clinical manifestations, treatment options and the immune response. The Netherlands Journal of Medicine. 2012; 70: 172-183.

11. Tognon M. High prevalence of BK poliyomavirus sequences in Human papillomavirus-16-positive precancerous cervical lesions. J Med Virol. 2011; 83: 1770-1776.

12. Boothpur R, Brennan DC. Human polyoma viruses and disease with emphasis on clinical BK and JC. J Clin Virol. 2010; 47: 306-312.

13. Neirynck V, Claes K, Naesens M, De Wever L, Pirenne J, Kuypers D. Renal cell carcinoma in the allograft: what is the role of Polyomavirus? Case Rep Nephrol Urol. 2012; 2: 125-134.

14. Bennett S, Broekema N, Imperiale M. BK polyomavirus: emerging pathogen. Microbes and Infection 2012; 14: 672-683.

15. Egli A, Infanti L, Dumoulin A, Buser A, Samaridis, Stebler C, Gosert R. et al. Prevalence of polyomavirus BK and JC infection and replication in 400 healthy blood donors. J Infect Dis. 2009; 199: 837-846.

16. Raeesi N, Gheissari A, Akrami M, Moghim S. Urinary BK virus excretion in children newly diagnosed with acute lymphoblastic leukemia. Int J Prev Med. 2012; 3: 402-407.

17. Chatterjee M, Weyandt TB, Frisque RJ. Identification of archetype and rearranged forms of BK virus in leukocytes from healthy individuals. J Med Virol. 2000; 60: 353-362.
18. Reploeg MD, Storch GA, Clifford DB. BK virus: a clinical review. Clin Infct Dis 2001; 33: 191-202.

19. Jin L, Gibson P., Booth JC, Clewly JP. Genomic typing of BK virus in clinical specimens by direct sequencing of polymerase chain reaction products. J Med Virol. 1994; 41: 11-17.

20. Kalvatchev Z, Slavov S, Shtereva M, Savova S. Reactivation of Polyomavirus hominis 1 (BKV) during pregnancy and the risk of mother-to-child transmission. J Clin Virol. 2008; 43: 328-329.

21. Bhattacharjee $S$, Chakraborty T. High reactivation of BK virus variants in Asian Indians with renal disorders and during pregnancy. Virus Genes 2004; 28: 157-168.

22. Jeffers LK, Madden V, Webster-Cyriaque J. BK virus has tropism for human salivary gland cells in vitro: Implication for transmission. Virology 2009; 394: 183-193.

23. Konietzny R, Fischer R, Ternette N, Wright C, Turney B, Chakera A. Detection of BK virus in urine from renal transplant subjects my mass spectrometry. Clin Proteomics. 2012; 9: 4.

24. Schowalter R, Reinhold W, Buck C. Entry tropism of BK and Merkel cell polyomaviruses in cell culture. PLoS One. 2012; 7: 42181.

25. Drachenberg CB, Papadimitriou JC, Ramos E. Histologic versus molecular diagnosis of BK polyomavirus-associated nephropathy: a shifting paradigm? Clin J Am Soc Nephrol. 2006; 1: 374-379.

26. Tong CYW, Hilton R, MacMohon EME, Brown L, Pantelidis P, Chrystie IL. Monitoring the progress of BK virus associated nephropathy in renal transplant recipients. Nephrol Dial Transplant. 2004; 19: 2598-2605.

27. Hoffman NG, Cook L, Atienza EE, Limaye AP, Jerome KR. Marked variability of BK virus load measurement using quantitative realtime PCR among commonly used assays. J Clin Microbiol. 2008; 46: 2671-2680.

28. Pang XL, Doucette K, LeBlanc B, Cocfield SM, Preiksaitis JK. Monitoring of polyomavirus BK virus. Viruria and viremia in renal allograft recipients by use of quantifitative real-time PCR assay: one-year prospective study. J Clin Microbiol. 2007; 45: 3568-3573.

29. Dropulic LK, Jones RJ. Polyomavirus BK infection in blood and marrow transplant recipients. Bone Marrow Transplant. 2008; 41: 11-18.

30. Held TK, Biel SS, Nitsche A. et al. Treatment of BK virus-associated hemorrhagic cystitis and simultaneous $\mathrm{CMV}$ reactivation with cidofovir. Bone Marrow Transplant 2000; 26: 347-50.

31. Naumnik B, Kowalewska J, Zalewski G, Charkiewicz R, Myśliwiec M. The Status of BK Polyomavirus Replication in Adult Renal Transplant Recipients in Northeastern Poland Transplant Proc. 2011; 43: 2976-84.

32. Cesaro S, Hirsch HH, Faraci M, Owoc-Lempach J, Beltrame A, Tendas A. et al. Cidofovir for BK virus-associated hemorrhagic cystitis: a retrospective study. Clin Infect Dis. 2009; 49: 233-240.

33. Gonzalez-Fraile MI, Canizo C, Caballero D. et al. Cidofovir treatment of human polyomavirus-associated acute haemorrhagic cystitis. Transpl Infect Dis 2001; 3: 44-46.

34. BohlDL, Brennan DC. BKvirus nephropathy and kidney transplantation. Clin J Am Soc Nephrol. 2007; 2: 36-37.

35. Comar M, Bonifacio D, Zanconati F, Di NApoil M, Isidoro E, Martini F. et al. High prevalence of BK poliyomavirus sequences in Human papillomavirus-16-positive precancerous cervical lesions. J Med Virol. 2011; 83: 1770-1776.

36. Fraase K., Hart J., Wu H., Pang X., Ma L., Grant F. et al. BK virus bas a potential co-factor for HPV in the development of cervical neoplasia. Ann Clin Lab Sci. 2011; 42: 130-134.

37. Fioriti D, Videtta M, Mischitelli M, Degener AM, Russo G, Giordano A. et al. Human poliomavirus BK: potential role in cancer. J Cell Physiol. 2005; 204: 402-406.

38. Hachana M, Amara K, Ziadi S, Gacem RB, Korbi S, Trimeche M. Investigation of human JC and BK polyomaviruses in breast carcinomas. Breast Cancer Res Treat. 2012; 133: 969-977.

39. Abol-Enein H. Infection: is it a cause of bladder cancer?, Scand J Urol Nephrol Suppl. 2008; 218: 79-84.

40. Palmieri A, Carinci F, Martinelli M, Spinelli G, LoMuzio L, Rubini C. et al. Absence of simian virus 40, BK, and JC polyomavirus DNA in squamous cell carcinoma limited to the oral cavity. Head and Neck 2010.

41. White MK, Khalili K. Signaling pathways and poliomavirus oncoproteins: Importance in malignant transformation. Gene Ther Mol Biol. 2004; 8: 19-30.

42. Tognon M, Corallini A, Martini F, Negrini M, Barbanti-Brodano G. Oncogenic transformation by $\mathrm{BK}$ virus and association with human tumors. Oncogene 2003; 22: 5192-5200.

43. Imperiale M. Oncogenic transformation by the human polyomaviruses. Oncogene 2001; 20: 7917-7923.

44. Corallini A, Tognon M, Negrini M, Barbanti-Brodano G. Evidence for BK Virus as a Human Tumor Virus. In: K. Khalili and G. L. Stoner (eds.). Human Polyomaviruses: Molecular and Clinical Perspectives. John Wiley \& Sons, Inc. 2002, New York, USA.

45. White MK, Khalili K. Polyomaviruses and human cancer: Molecular mechanisms underlying patterns of tumorigenesis. Virology 2004; 324: 1-16. 